\title{
Factores asociados al rendimiento académico en estudiantes universitarios desde el nivel socioeconómico: Un estudio en la Universidad de Costa Rica
}

\author{
Factors associated to academic performance in university students from the \\ socio-economic perspective: A study at the University of Costa Rica
}

\author{
Guiselle María Garbanzo Vargas \\ Escuela de Administración Educativa \\ Universidad de Costa Rica \\ San José, Costa Rica \\ gmgarban@gmail.com
}

Recibido 6 de mayo de 2013 • Corregido 15 de julio de 2013 • Aceptado 31 de julio de 2013

1 Doctora en Educación de la Universidad de Costa Rica con pasantía de investigación en la Universidad de Salamanca, España, magister en Administración Educativa de la Universidad de Costa Rica, licenciada en Ciencias de la Educación con énfasis en Orientación de la Universidad de Costa Rica, licenciada en Administración con énfasis en Recursos Humanos de la Universidad Nacional y bachiller en Ciencias de la Educación con énfasis en Orientación de la Universidad de Costa Rica. Ha realizado pasantías académicas en la Universidad de Helsinki, Finlandia; Universidad de Murcia, España; Universidad de Montreal - Organización Universitaria Interamericana; también en la Unesco, Suiza, Ginebra. Además, ha participado en distintos congresos internacionales, entre ellos, en Brasil, México, Argentina y España. Ha publicado distintos artículos en el campo de la educación superior pública y de la administración de la educación en revistas nacionales e internacionales, ha impartido varias conferencias en el ámbito nacional e internacional, ha dirigido el II, III y IV Congreso Internacional de Administración de la Educación y ha sido directora de la Escuela de Administración Educativa, Facultad de Educación de la Universidad de Costa Rica en dos períodos. Actualmente es la directora del Posgrado en Ciencias de la Educación con énfasis en Administración Educativa, directora de la Revista Científica Gestión de la Educación. También es docente e investigadora en la Escuela de Administración Educativa de la Facultad de Educación de la Universidad de Costa Rica y coordina, para Centroamérica, el Curso de Gestión de Liderazgo Universitario. 
URL: http://www.una.ac.cr/educare

CORREO: educare@una.cr

Resumen. Por ser el desempeño académico de la población estudiantil en la educación superior uno de los indicadores de calidad más sobresalientes y trascendentales de la labor académica del sistema de educación superior, se realiza una investigación de corte cuantitativa, en la cual se trabaja con una cohorte de estudiantes universitarios en la educación superior, específicamente en la Universidad de Costa Rica, que en el momento del estudio se encontraban graduados o en los últimos años de su carrera, se les aplicó un cuestionario en forma personalizado. El estudio indaga el tema de los factores asociados al rendimiento académico desde el nivel socioeconómico en estudiantes universitarios y su objetivo general consiste en analizar los factores asociados al rendimiento académico en estudiantes que, por su condición socioeconómica, se les asignó la máxima categoría de beca, y estudiantes que no solicitaron beca por esta condición de carreras de alta y baja demanda de la Universidad de Costa Rica. De esta forma, se aborda la problemática del rendimiento académico, desde el nivel socioeconómico de sus estudiantes, esta variable se considera de importancia para ofrecer un marco explicativo y proporcionar insumos a las políticas institucionales en el campo de la educación superior pública. El estudio permitió ratificar que el rendimiento académico es altamente multicausal y complejo; es el producto de la interacción de múltiples factores sociales, personales, institucionales-académicos que pueden variar de una población a otra, así como la existencia de diferencias significativas entre las variables lineales: índice de satisfacción universitaria, índice de hábitos de estudio, índice de apoyo en los estudios universitarios, índice de satisfacción con los profesores e índice de nivel socioeconómico; sin embargo, se mostró que no producen diferencias en las variables más importantes, como lo son el promedio ponderado y la nota de admisión.

Palabras claves. Educación superior, rendimiento académico, rendimiento académico en estudiantes universitarios, rendimiento académico, condición socioeconómica, Universidad de Costa Rica.

Abstract. Since the academic performance of higher education students is one of the most outstanding and far-reaching quality indicators of the academic activity, a quantitative research was conducted with a cohort of students from the University of Costa Rica, who were graduated or in the last years of their study program. A questionnaire was applied to these students in a personalized way. The study refers to the factors associated to academic performance from the socioeconomic perspective. The general objective was to analyze the factors associated to the academic performance of those students with the highest scholarship category because of their socio-economic situation, and students who did not request a scholarship because of the high/low demand of study programs at the University of Costa Rica. In this way, this research examines the problem of academic performance based on the socio-economic situation of students; this variable is very important for having an explanatory framework and providing input related to institutional policies in the area of public higher education. The study helped us to confirm that academic performance is a very complex multi-causal process that results from the interaction of multiple social, personal, academic-institutional factors, which may vary from one population to another. It also confirmed the existence of significant differences between linear variables: university satisfaction index, study habits index, index of university studies support, satisfaction rate about teachers, and socioeconomic situation; however, the study reported that there are no differences in the most important variables, including grade point average and admission score.

Keywords. Higher education, academic performance, academic performance of university students, academic performance, socio-economic situation, University of Costa Rica. 
Este artículo deriva de una investigación anterior denominada Factores asociados al rendimiento académico en estudiantes universitarios desde el nivel socioeconómico: Un estudio en la Universidad de Costa Rica (Garbanzo, 2011).

En los albores del presente siglo, a escala mundial, la educación superior se caracteriza por una demanda sin precedentes, gran diversidad en su oferta académica, así como la necesidad de una cultura de innovación en forma constante con reformas que le permitan responder a las demandas de la emergente sociedad del conocimiento. A su vez, experimenta fuertes cuestionamientos sobre su calidad, principalmente, por una mayor conciencia de la importancia trascendental que representa, en el actual mundo competitivo, para el desarrollo económico, social, político y cultural ante las demandas y desafíos de eficiencia que la sociedad globalizada espera de ella.

Uno de los indicadores de calidad más sobresalientes y trascendentales de la labor académica de las organizaciones educativas lo representa el desempeño académico de la población estudiantil, registrado en las distintas materias de los planes curriculares que cursan. Este componente académico de los estudiantes es uno de los principales indicadores que ofrece un parámetro aceptable de la eficiencia, en las instituciones educativas en sus distintos niveles.

El rendimiento académico es la conjugación de distintos factores multicausuales que inciden en el resultado académico, en el que interactúan elementos sociodemográficos, psicosociales, pedagógicos, institucionales y socioeconómicos; entre ellos, elementos tan variados como: la motivación, la ansiedad, la autoestima, la percepción del clima académico, el entusiasmo, el docente, el sentido de propósito y demás (Montero Villalobos, 2004b). Son muchos los factores que pueden presentar asociación con el resultado académico, los cuales no siempre son los mismos, razón por la cual es un tema que amerita constante investigación y contar con información precisa en la toma de decisiones institucionales.

Las universidades en Latinoamérica, ante esta importante situación, y con el propósito de conocer los posibles factores asociados a los resultados del rendimiento académico, presentan diferentes estudios al respecto; sin embargo, no es frecuente encontrar información disponible que haya abordado la problemática del rendimiento académico, desde el nivel socioeconómico de sus estudiantes, variable de suma importancia para ofrecer un marco explicativo y proporcionar insumos a las políticas institucionales, de manera que se tome en cuenta la particularidad de los estudiantes, en este caso, según el nivel socioeconómico.

Ante las exigencias de la actual sociedad, es relevante que las universidades profundicen sus indicadores de rendimiento académico en diferentes ámbitos metodológicos y teóricos desde la investigación. Entre estos, el nivel socioeconómico resulta una variable por considerar para poder ofrecer un panorama más amplio, como fuente de información notable, en la toma de decisiones del quehacer de las instituciones educativas, desde este ámbito del saber. Estudios sobre factores asociados al rendimiento académico en las instituciones educativas, definitivamente, son parámetros de su eficacia y eficiencia en respuesta a su pertinencia social (UNESCO, 2002). 
URL: http://www.una.ac.cr/educare

CORREO: educare@una.cr

Es así que, en la presente investigación, se indaga el tema de los factores asociados al rendimiento académico desde el nivel socioeconómico en estudiantes universitarios, a diferencia de la mayoría de estudios, esta retoma el tema desde el nivel socioeconómico; campo de estudio que presenta un importante vacío en la interpretación de este fenómeno, en especial en la educación superior pública, que, por su naturaleza, tiene un llamado social con las poblaciones estudiantiles.

Este artículo se propone analizar los factores asociados al rendimiento académico en estudiantes que, por su condición socioeconómica, se les asignó la máxima categoría de beca y estudiantes que no solicitaron beca por esta condición de carreras de alta y baja demanda de la Universidad de Costa Rica. También interesa contrastar la teoría desarrollada a escala nacional e internacional sobre rendimiento académico, con la situación de la población en estudio.

Específicamente, se trata de constatar, en qué medida, los factores asociados al rendimiento académico estudiantil, en estudiantes con la máxima categoría de beca por condición socioeconómica, difieren de los estudiantes que no solicitaron beca por esta condición; determinar elementos teóricos que permitan retroalimentar un marco explicativo sobre el rendimiento académico en la educación superior pública, en estudiantes con la máxima categoría de beca por condición socioeconómica; generar hipótesis relacionadas con los factores específicos que están asociados al rendimiento académico, en estudiantes con la máxima categoría de beca por condición socioeconómica y estudiantes que no solicitaron beca por esta condición socioeconómica; establecer factores institucionales, pedagógicos, psicosociales y sociodemográficos que se asocian al rendimiento académico de estudiantes de carreras de alta y baja demanda con estudiantes con la máxima categoría de beca por condición socioeconómica y estudiantes que no solicitaron beca por esta condición socioeconómica en la Universidad de Costa Rica.

\section{Componentes teóricos asociados a la investigación}

\section{Rendimiento académico en general y desde la educación superior}

El rendimiento académico en estudiantes universitarios representa un indicador estratégico para la valoración de la calidad educativa en la educación superior, y es el resultado de la unión de diferentes factores que intervienen en la vida académica del estudiante (De Miguel et al., 2002). Se le define como el valor atribuido al logro del estudiante en su desempeño académico, mediante las calificaciones obtenidas. Casi siempre involucra una evaluación cuantitativa del aprovechamiento del estudiante, ya sea satisfactorio o no, e implica deserción o éxito académico (Pérez, Ramón y Sánchez, 2000; Vélez y Roa, 2005).

El valor de las notas académicas alcanzadas representa el mejor indicador para estimar el rendimiento académico y se asume que las notas representan los logros en los diferentes componentes del aprendizaje en la vida académica. Estos componentes incluyen aspectos personales, académicos y sociales (Pérez et al., 2000; Vélez y Roa, 2005). 
De manera integral, hay consenso en que el rendimiento académico engloba distintas variables; complejas por sí mismas, tales como pedagógicas, institucionales, sociodemográficas y psicosociales, según se indica por Tournon (1984), citado por Montero, Villalobos y Valverde, 2007):

... Un resultado del aprendizaje, suscitado por la intervención pedagógica del profesor o la profesora, y producido en el alumno. [sic] No es el producto analítico de una única aptitud, sino más bien el resultado sintético de una suma (nunca bien conocida) de elementos que actúan en, y [sic] desde la persona que aprende, tales como factores institucionales, pedagógicos, psicosociales y sociodemográficos. (p. 217)

Los factores institucionales asociados al rendimiento académico son definidos como una serie de características estructurales y funcionales, que varían según la particularidad de cada institución. Dentro de estos factores, se encuentran aspectos como los horarios de los distintos cursos, y otros en relación directa con la carrera y el ambiente institucional (Montero et al., 2007).

La sociedad y el individuo actúan como un binomio de interrelaciones, por ello, al conceptualizar los factores psicosociales asociados al rendimiento académico, hay que tomar en cuenta las conexiones que se plasman entre la sociedad y la persona, pues desde el punto de vista de las relaciones, ambas interactúan e influyen entre sí. Incluyen aspectos por considerar como la autoestima y su relación con el entorno académico, motivación, percepción en torno al clima académico desde la óptica del estudiante y ansiedad. La ansiedad no es considerada como una variable predictora del rendimiento académico, asume importancia en la medida en que modifica el valor predictivo de variables tales como la motivación y la inteligencia (Montero et al., 2007). También, en este aspecto se consideran factores asociados a la competencia cognitiva, aspiraciones académicas del estudiante hacia lo que desea lograr.

Entre los factores pedagógicos, asumen importancia la influencia de la función del docente, relaciones entre el alumnado que el profesorado establezca, capacidad de comunicación al dirigirse hacia el estudiantado, interés académico en estudiantes, que el personal docente sea capaz de establecer. En este aspecto, aquellos profesores y profesoras accesibles, que muestran interés en lo que enseñan y consideren a sus estudiantes como personas integrales, tienden a mostrar una influencia positiva en el rendimiento académico (Centra, 1970, en Latiesa, 1992, ambos citados por Montero et al., 2007). Este factor también toma en cuenta recursos didácticos, estrategias de enseñanza y métodos de evaluación.

En los factores sociodemográficos se toman en cuenta aspectos como nivel económico del grupo familiar, entorno socieoecónomico y sociocultural (capital cultural), sexo, modalidad 
URL: http://www.una.ac.cr/educare

CORREO: educare@una.cr

de colegio, nivel educativo del padre y de la madre. Los factores culturales y sociales del entorno familiar favorecen el desarrollo intelectual del individuo, por lo general son considerados una forma del denominado capital cultural (Montero et al., 2007).

Es así como cada universidad y según su normativa, determina los criterios evaluativos para dar una valoración general del rendimiento académico, identificado como el promedio ponderado. Esta valoración toma en cuenta aspectos relacionados con la nota académica en cada una de las materias, el número de créditos y la cantidad de materias. No se debe olvidar que las calificaciones reflejan también factores personales, sociales e institucionales.

La valoración del rendimiento académico en la educación superior es imprecisa, debido a que se construye con base en las notas obtenidas. Por ello, se reconoce la necesidad de diferenciar entre el rendimiento académico inmediato, que son las notas, y el mediato, referente a los logros profesionales y personales del estudiantado (Rodríguez, Fita y Torrado 2004). La valoración del rendimiento académico establece la relación entre lo que el estudiante aprende y lo que se alcanza en el proceso de enseñanza aprendizaje, como producto del trabajo académico del estudiante en las distintas actividades en las que se desempeñó ante sus profesores (Rodríguez et al., 2004).

Por sus características y complejidad, el abordaje teórico del rendimiento académico suele ser arriesgado y polémico, razón por la cual se limita, actualmente, a una generalización conceptual, pues el contexto, las características de los estudiantes, las metodologías evaluativas empleadas, las técnicas didácticas, entre otras, condicionan, significativamente, sus resultados.

Está demostrado que existen factores de distinta naturaleza que intervienen en el rendimiento académico, lo que lo convierte en un fenómeno multicausal, en el que se deben analizar componentes psicosociales, sociodemográficos, pedagógicos, socioeconómicos e institucionales, que al interactuar entre sí y de manera conjunta, determinan el resultado final; lo que conlleva una complejidad explicativa que no se puede obviar. Por la relevancia teórica en esta investigación, cada uno de los principales factores que influyen en el rendimiento académico se desarrollan a continuación.

\section{Conceptualización del nivel socioeconómico}

El nivel socioeconómico incluye tanto rasgos cuantitativos como cualitativos, solo se puede pertenecer a un nivel socioeconómico y se recomienda que su medida sea nacional. Es una medida estable a corto plazo, debido a las variables que interactúan en forma constante en una sociedad determinada. Por lo tanto, el nivel socioeconómico es un atributo del hogar que lo comparten todos sus miembros y se determina mediante distintas variables. 
El nivel socioeconómico es una construcción teórica y empírica, no es comprensible como un concepto simple de una determinada medida en forma directa (Barberena, 2005). Su construcción no es homogénea en los distintos países, no posee estabilidad conceptual, está sujeta a los cambios sociales.

Usualmente, tiende a confundirse el nivel socioeconómico con el concepto de clase social. Al respecto, es importante considerar que el primero se refiere a una serie de características del hogar relacionadas con la capacidad de consumo de un grupo familiar. Por su lado, clase social indica un grupo de pertenencia de acuerdo con ciertas características, las cuales son definidas socialmente.

En lo que a los niveles socioeconómicos se refiere, desde el punto de vista de la teoría de la estratificación social, en la sociedad costarricense, se consideran los niveles socioeconómicos como una característica que comparten sus integrantes del hogar, se determina por un conjunto de variables relacionadas con la capacidad de consumo que tiene un grupo familiar.

Es así que investigar los factores asociados al rendimiento académico, según nivel socioeconómico, es necesario, ya que estos pueden incidir en forma positiva o negativa, y ofrecen importantes insumos en las políticas institucionales que buscan elevar el desempeño académico (Armenta, Pacheco y Pineda 2008).

La estratificación social realizada por el Decimoquinto informe (Programa Estado de la Nación en Desarrollo Humano Sostenible, 2009) sirve de parámetro para entender a qué se refiere la Universidad de Costa Rica en cuanto a niveles socioeconómicos para categorizar a los estudiantes según la condición socioeconómica, pues la Universidad está inserta en la sociedad costarricense y se guía por sus parámetros; sin embargo, no ha habido en la Universidad una clasificación de los estudiantes según la estratificación social que utiliza la sociedad costarricense, pues es claro que la Universidad de Costa Rica tiene estudiantes según esta categoría de clases sociales y, para clasificarlos, acude a sus propios indicadores.

Para los objetivos de este estudio, se considera a los estudiantes por la condición socioeconómica, según la clasificación que la Oficina de Atención Socioeconómica de la Universidad de Costa Rica utiliza en la asignación de becas por necesidad socioeconómica. Se clasificaron los estudiantes en la categoría de bajos niveles socioeconómicos como aquellos que por su condición socioeconómica solicitaron ayuda y se les otorgó la máxima colaboración por necesidad socioeconómica, denominada dentro de la Universidad como "becados once."

Es importante indicar que la máxima categoría de ayuda socioeconómica proporcionada por la Universidad de Costa Rica se hace mediante una serie de variables tales como: ingreso per cápita, colegio de procedencia, imponible al ruedo e imponible a la propiedad. Todas estas variables se actualizan mediante un conjunto de indicadores como inflación, línea de pobreza, ingreso per cápita por quintil, aranceles de cobro, índice de 
URL: http://www.una.ac.cr/educare

CORREO: educare@una.cr

precios al consumidor, pensión del Régimen invalidez, vejez y muerte, pensión de Régimen no contributivo y salarios mínimos (Universidad de Costa Rica. Oficina de Becas y Atención Socioeconómica, 2009).

Los estudiantes que no pertenecen al bajo nivel socioeconómico, se determinaron como aquellos que no solicitaron ningún tipo de ayuda socioeconómica y se consideran para efectos institucionales como estudiantes sin beca.

\section{Relación entre nivel socioeconómico y rendimiento académico en la educación superior}

Existe una estrecha y significativa relación entre el nivel socioeconómico y la escolaridad, se da una asociación inversa: cuanto más años de escolaridad, menor será la incidencia en la pobreza. La educación posee una importante capacidad predictiva del nivel socioeconómico de una población (Programa Estado de la Nación en Desarrollo Humano Sostenible, 2009).

El nivel socioeconómico asociado al rendimiento académico ha sido objeto de distintas investigaciones en el campo educativo, incluyendo el universitario. En variados estudios, como el de García y San Segundo (2001), se evidencia en forma precisa y significativa una asociación entre el rendimiento académico y el nivel socioeconómico, de manera que cuanto mayor es el nivel socioeconómico, mayor tiende a ser el rendimiento académico del alumnado. Es así como este componente socioeconómico y su asociación con el rendimiento académico en la educación superior ha evidenciado una relación positiva; sin embargo, tampoco se puede afirmar como una asociación persistente.

En el tema de las diferencias entre el rendimiento académico y el nivel socioeconómico en la educación superior, los aportes teóricos han demostrado que no, necesariamente, el alto nivel socioeconómico está asociado en forma significativa a un buen rendimiento académico. Se ha encontrado que, en algunos casos, que estudiantes de niveles socioeconómicos considerados intermedios o medios han resultado con valores altos en lo que respecta al rendimiento académico; pero no sucede lo mismo con aquellos universitarios ubicados en niveles socioeconómicos bajos o altos, es decir, no se asocian necesariamente con valores altos en lo que respecta al rendimiento académico (Gregorat, Soria, García y Seco, 2009).

El nivel económico como variable categórica ordinal suele ser representada tomando en cuenta como referencia la canasta familiar, ingresos per capita del hogar, al menos así fue estudiado en la educación superior por Gregorat et al. (2009).

El tamaño familiar; la condición del alumno referente a si trabaja, además de estudiar; el nivel de educación del jefe de familia, y el ingreso económico mensual del estudiante han sido considerados por Tonconi (2010) para indagar la relación existente entre el nivel socioeconómico y el rendimiento académico. Estas variables han sido de gran preocupación en sociedades como 
Perú, debido a los bajos resultados académicos en la población universitaria, donde este fracaso educativo se ha transformado en abandono de las aulas universitarias por parte del alumnado, principalmente por el deseo de resolver su situación socioeconómica.

Armenta, Pacheco y Pineda (2008) también han empleado la relación entre nivel socioeconómico y el rendimiento académico en la educación superior, con el fin de obtener una orientación sobre cómo estas variables interactúan en los estudiantes universitarios y poder trabajar con un conjunto de causas en las que se puedan originar problemas en torno al rendimiento académico.

Los hijos que crecen en hogares de bajos niveles socioeconómicos presentan una marcada diferencia en el desarrollo psicomotor en sus primeros años en comparación con los de niveles socioeconómicos altos. Estos datos fueron demostrados en un estudio realizado en Chile para el Banco Mundial en 1996 (Rivero, 1999). La anterior situación explica en gran medida el porqué del fracaso educativo en las poblaciones de bajos niveles socioeconómicos.

Los rendimientos académicos están influidos no solo por factores pedagógicos, institucionales y sociales, sino que también pesa enormemente la condición socioeconómica (Gamhi y Santander, 1998). Esta condición no es exclusiva para la educación superior, también se traslapa en los otros niveles educativos.

\section{Especificidad metodológica del estudio}

\section{Tipo de investigación}

La investigación que se plantea, se llevó a cabo mediante la utilización de técnicas de recolección y análisis cuantitativo. Se utilizó un cuestionario que permitió abordar el tema en estudio.

Se relacionó el rendimiento académico como variable dependiente con una serie de variables independientes que se cree son predictoras del rendimiento académico, con estudiantes con la máxima categoría de beca y estudiantes que no solicitaron beca, también con estudiantes de carreras de baja demanda y de alta demanda en la Universidad de Costa Rica. Se consideraron grupos de comparación con estos estudiantes; verificando así, si los factores asociados al rendimiento académico, que interesan en el estudio, son exclusivos de estudiantes que poseen la máxima categoría de beca por su condición socioeconómica, o también los comparten estudiantes que no solicitaron beca por esta condición. El detalle de estas variables se muestra en la tabla 1. 
URL: http://www.una.ac.cr/educare

CORREO: educare@una.cr
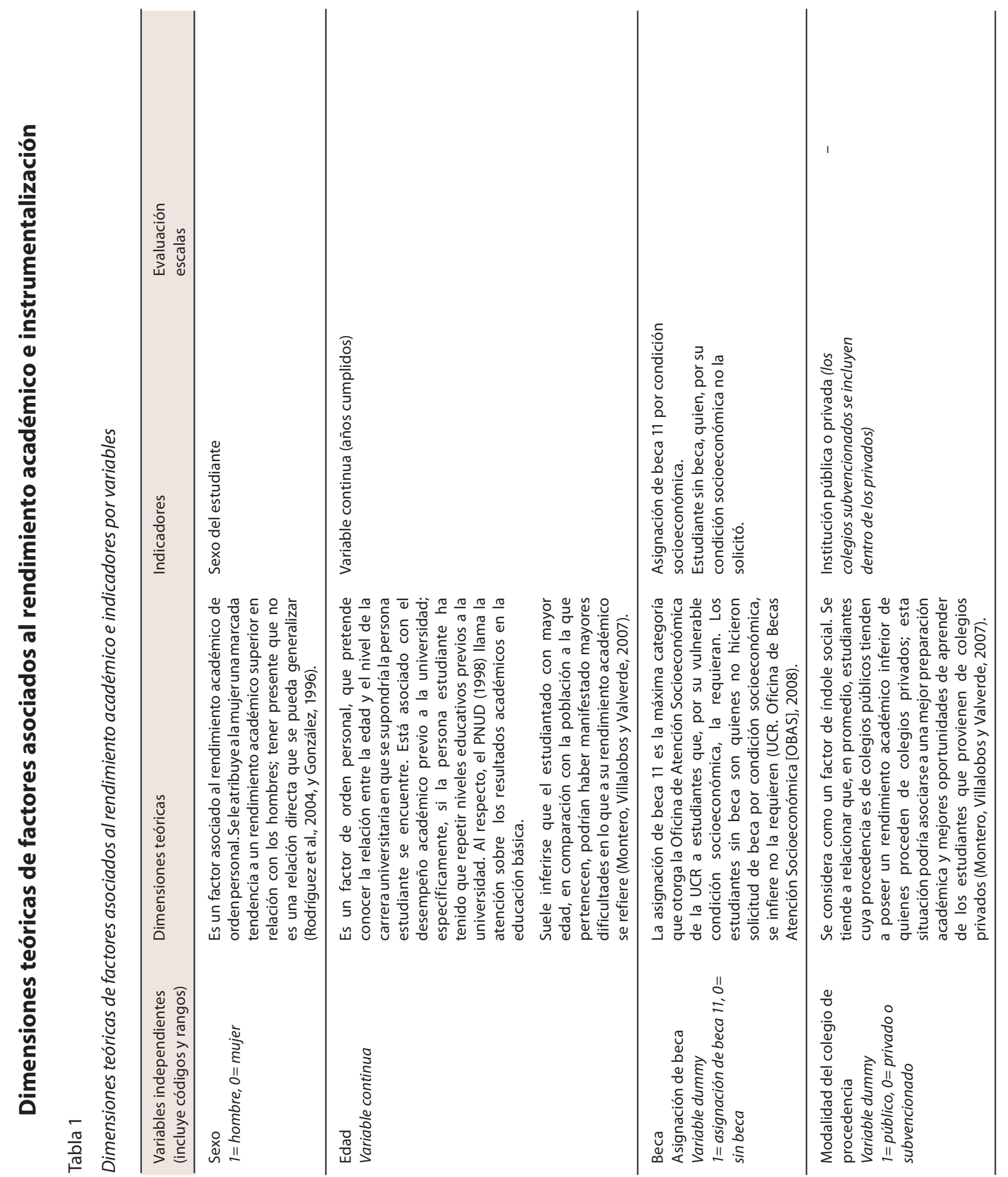

66

Guiselle María Garbanzo Vargas

$\Theta \odot \Theta \Theta$

Artículo protegido por licencia Creative Commons 
URL: http://www.una.ac.cr/educare
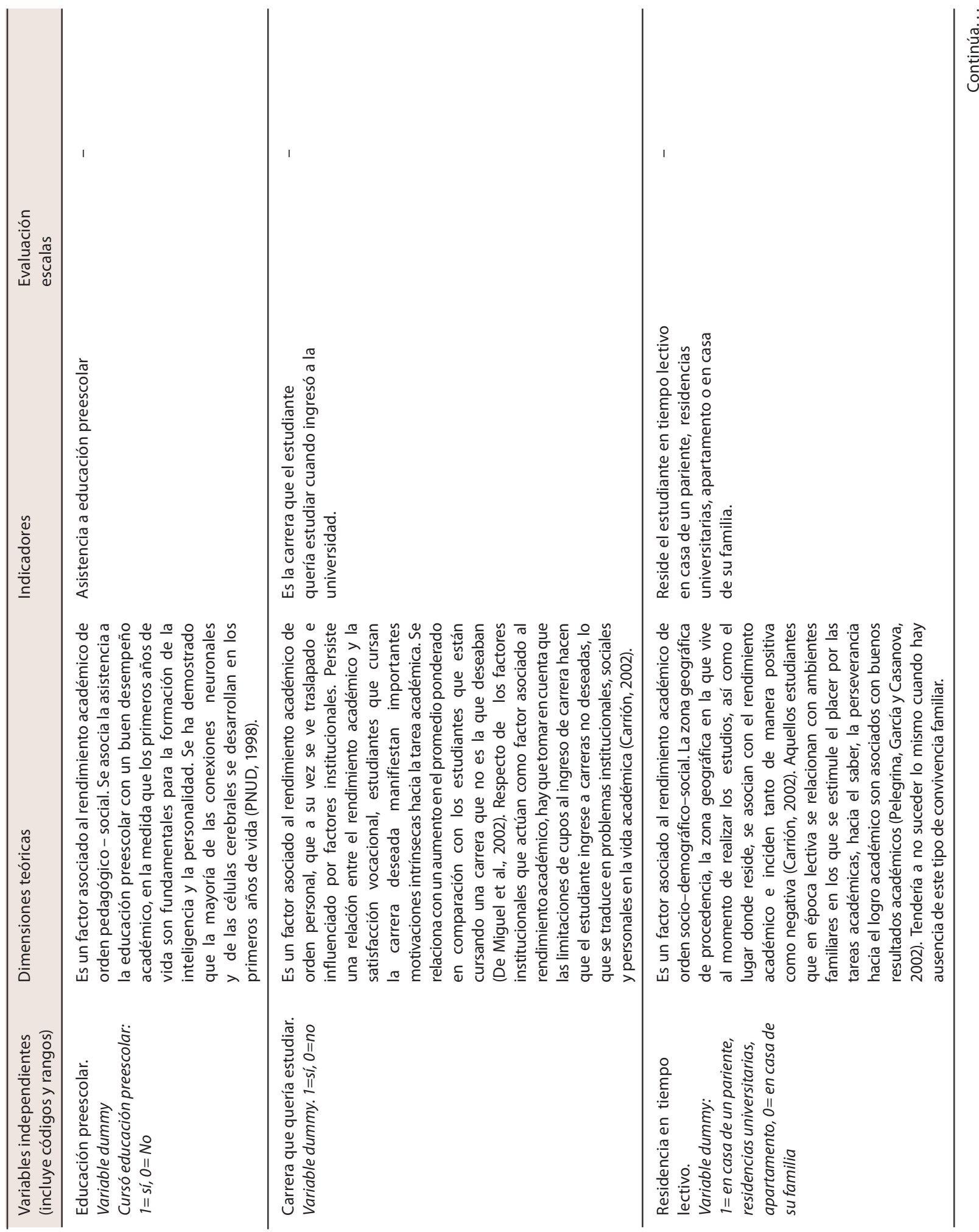
URL: http://www.una.ac.cr/educare

CORREO: educare@una.cr

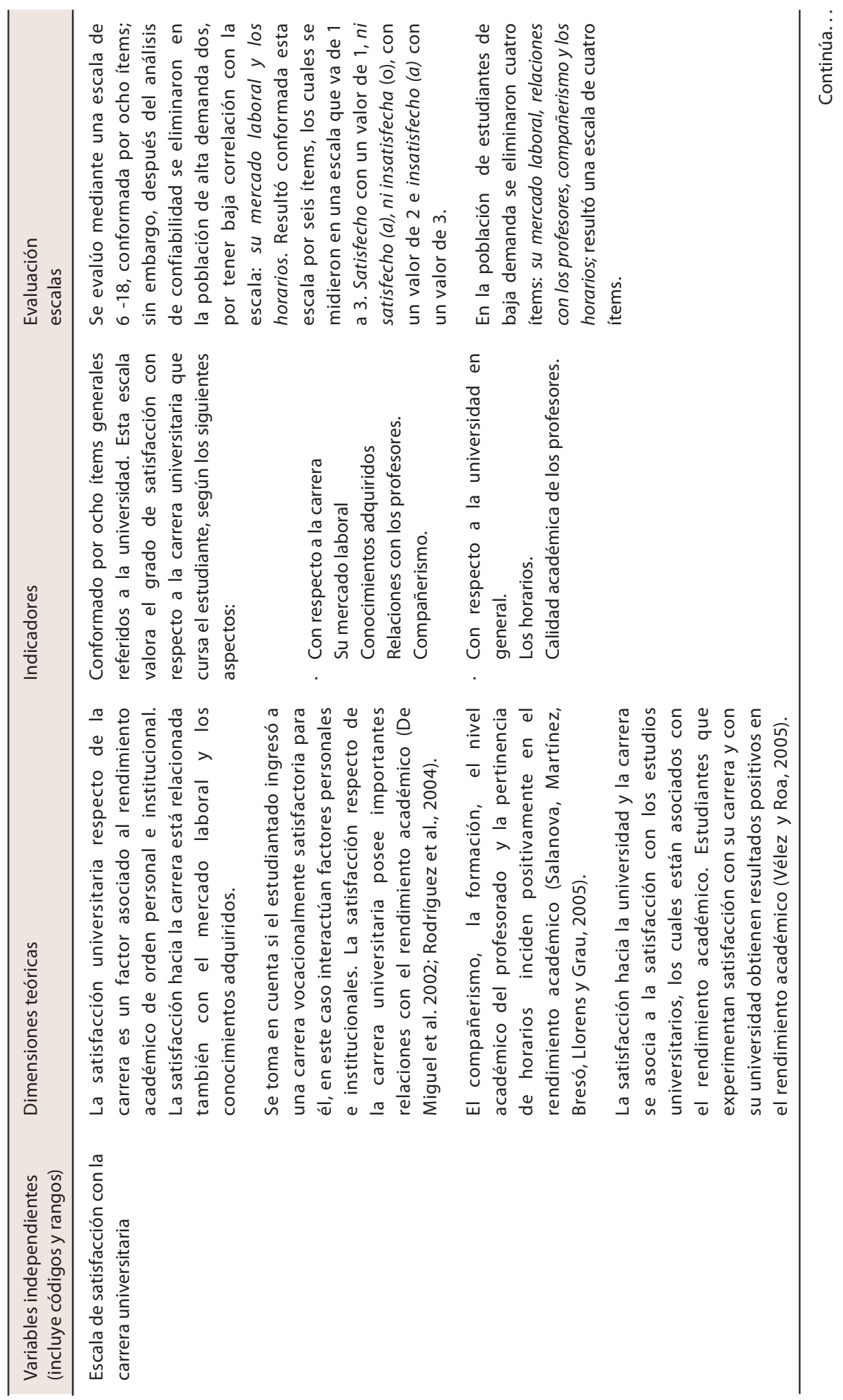


URL: http://www.una.ac.cr/educare

CORREO: educare@una.cr

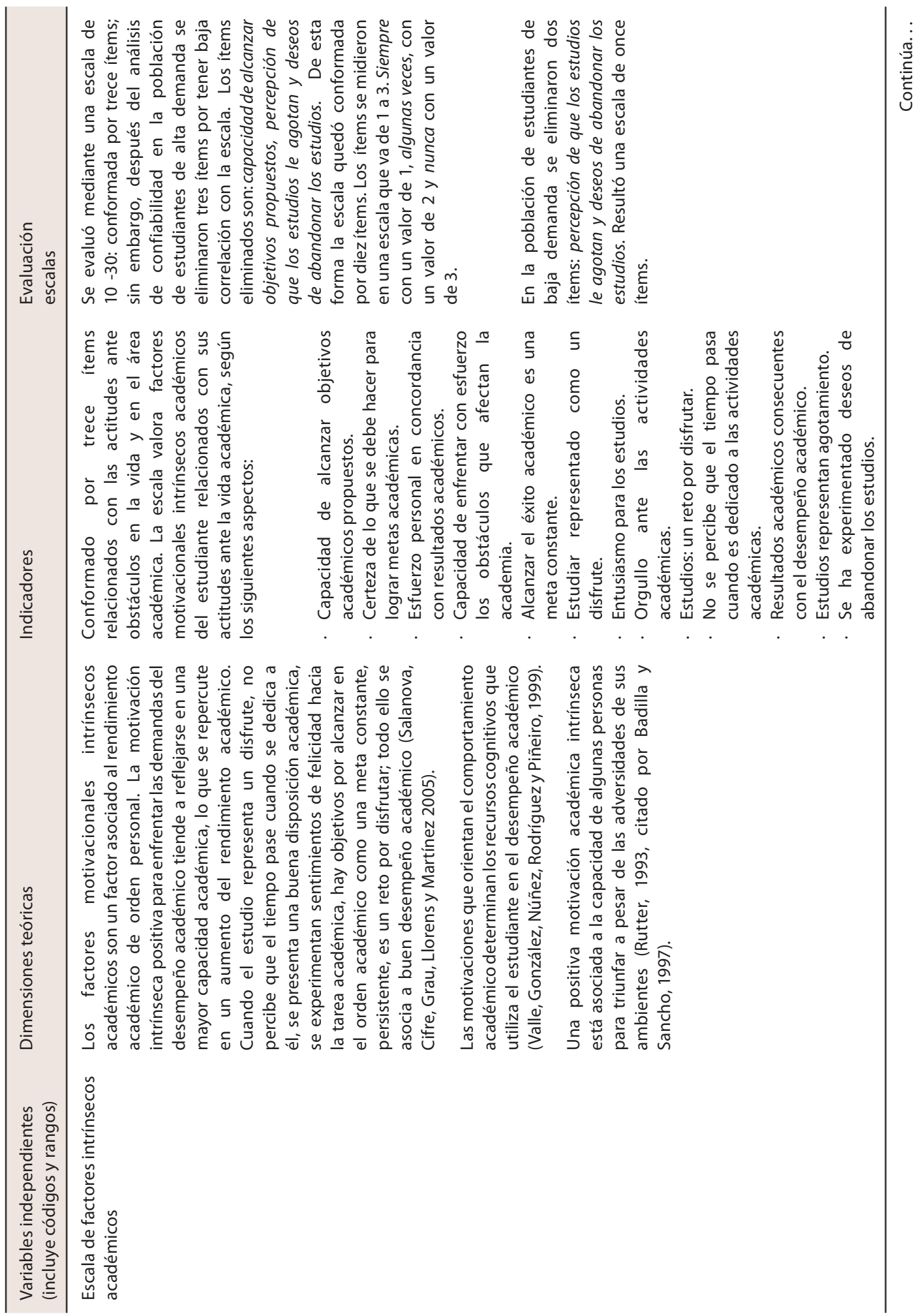


URL: http://www.una.ac.cr/educare

CORREO: educare@una.cr
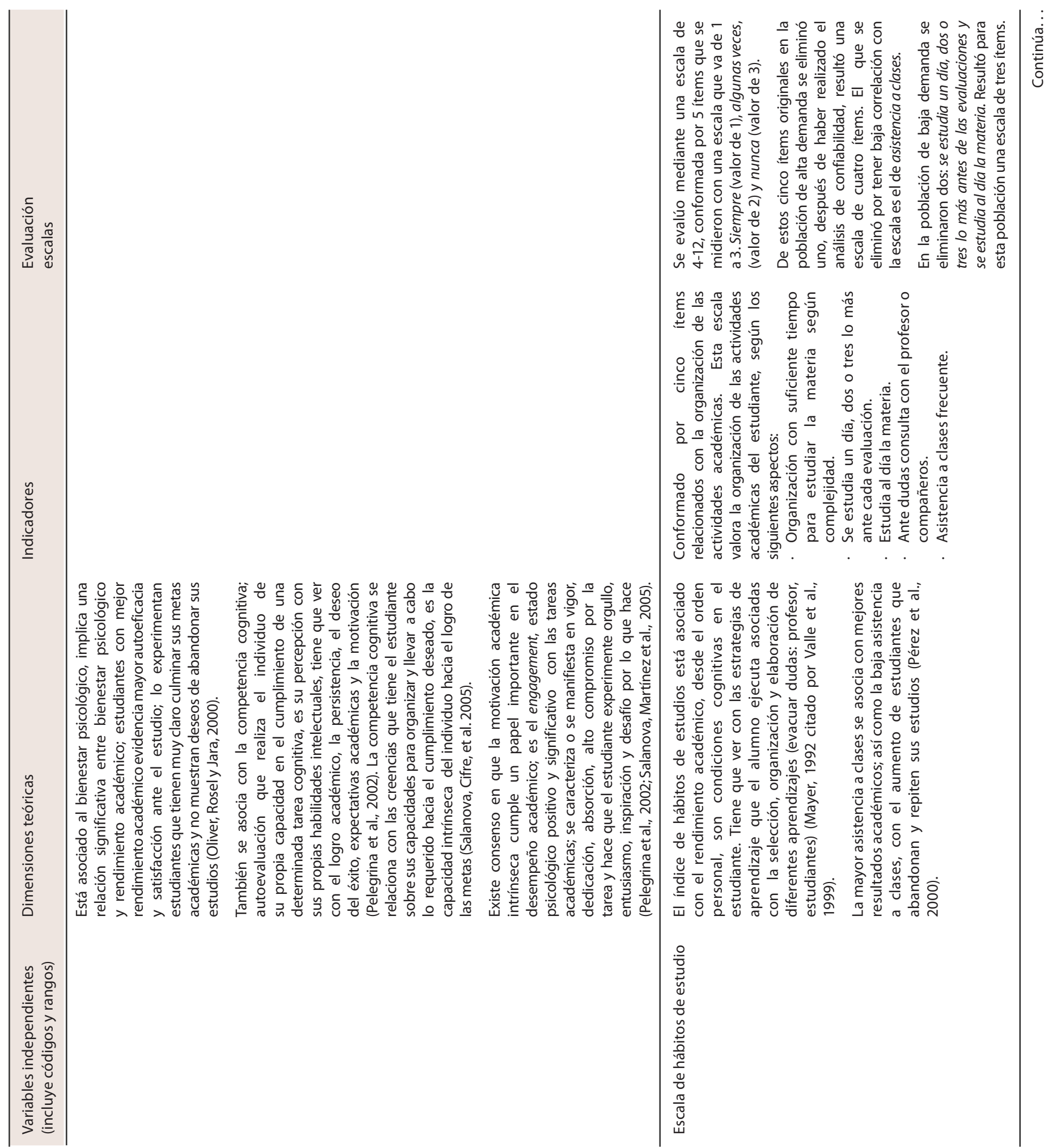

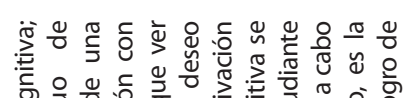

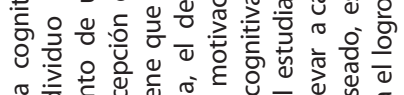

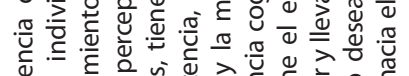

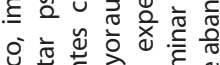

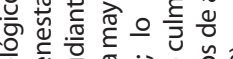

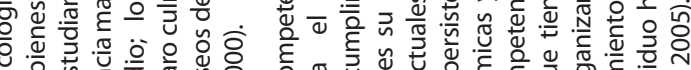

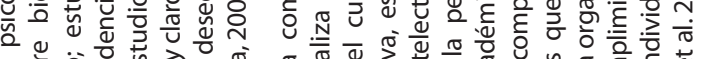

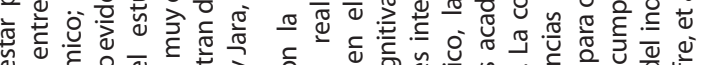

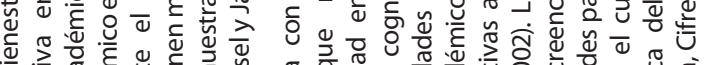

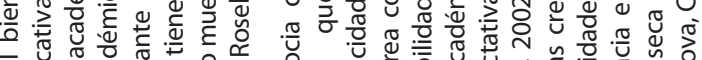

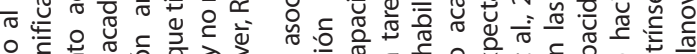

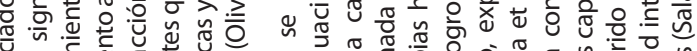

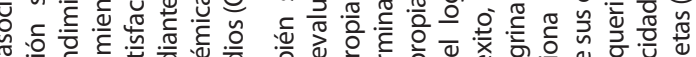

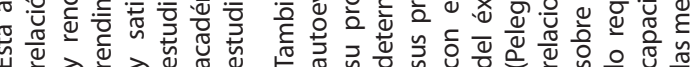

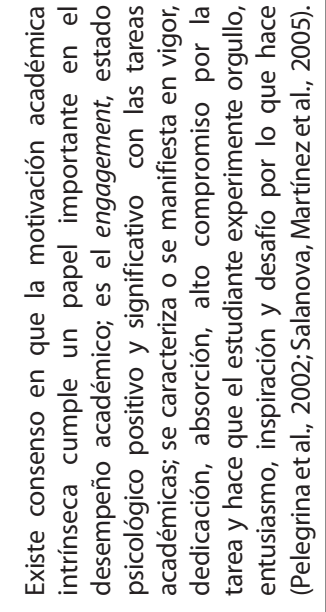

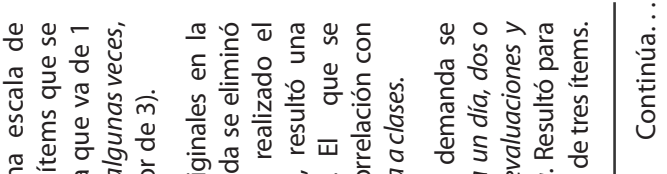


URL: http://www.una.ac.cr/educare

CORREO: educare@una.cr

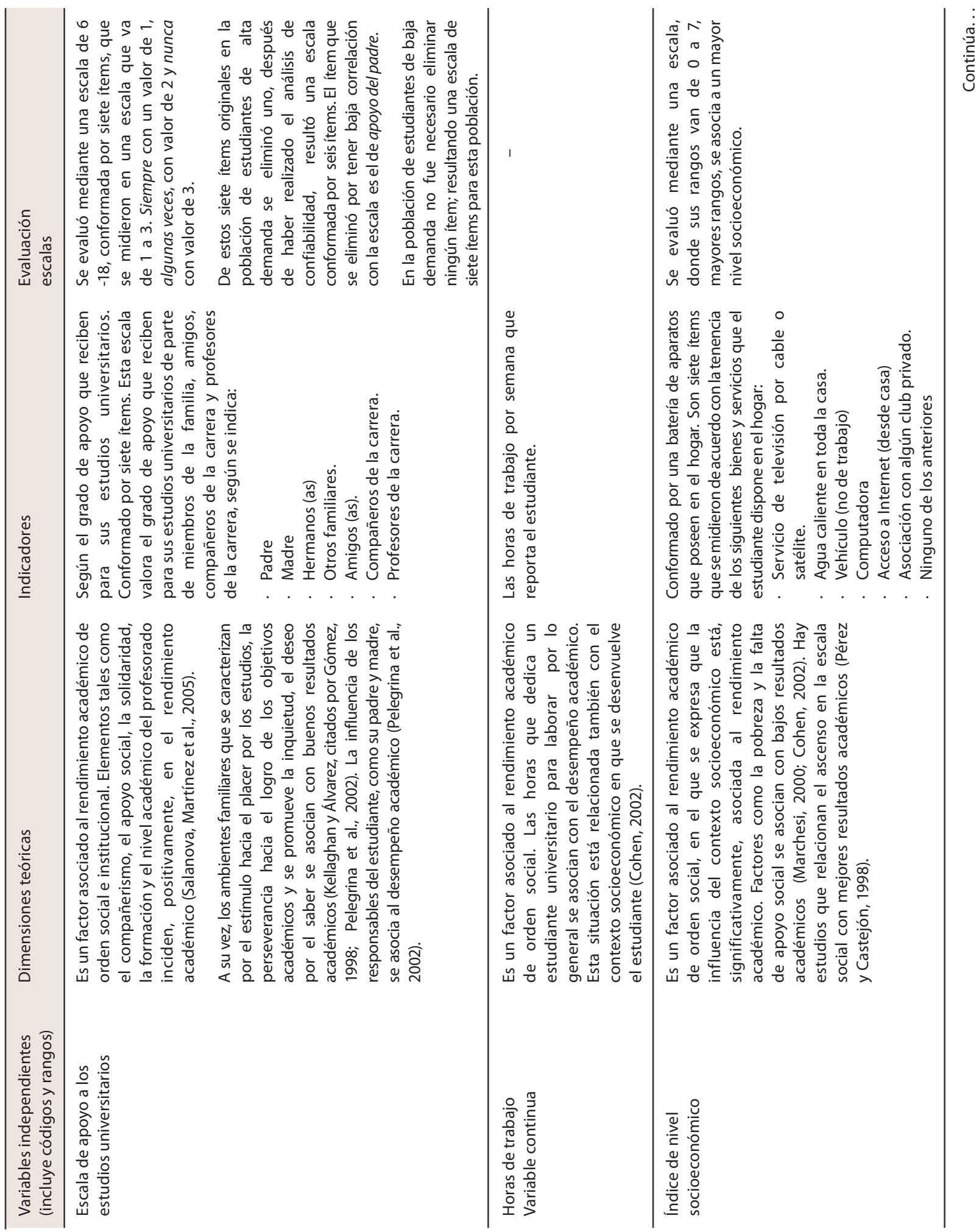


URL: http://www.una.ac.cr/educare

CORREO: educare@una.cr
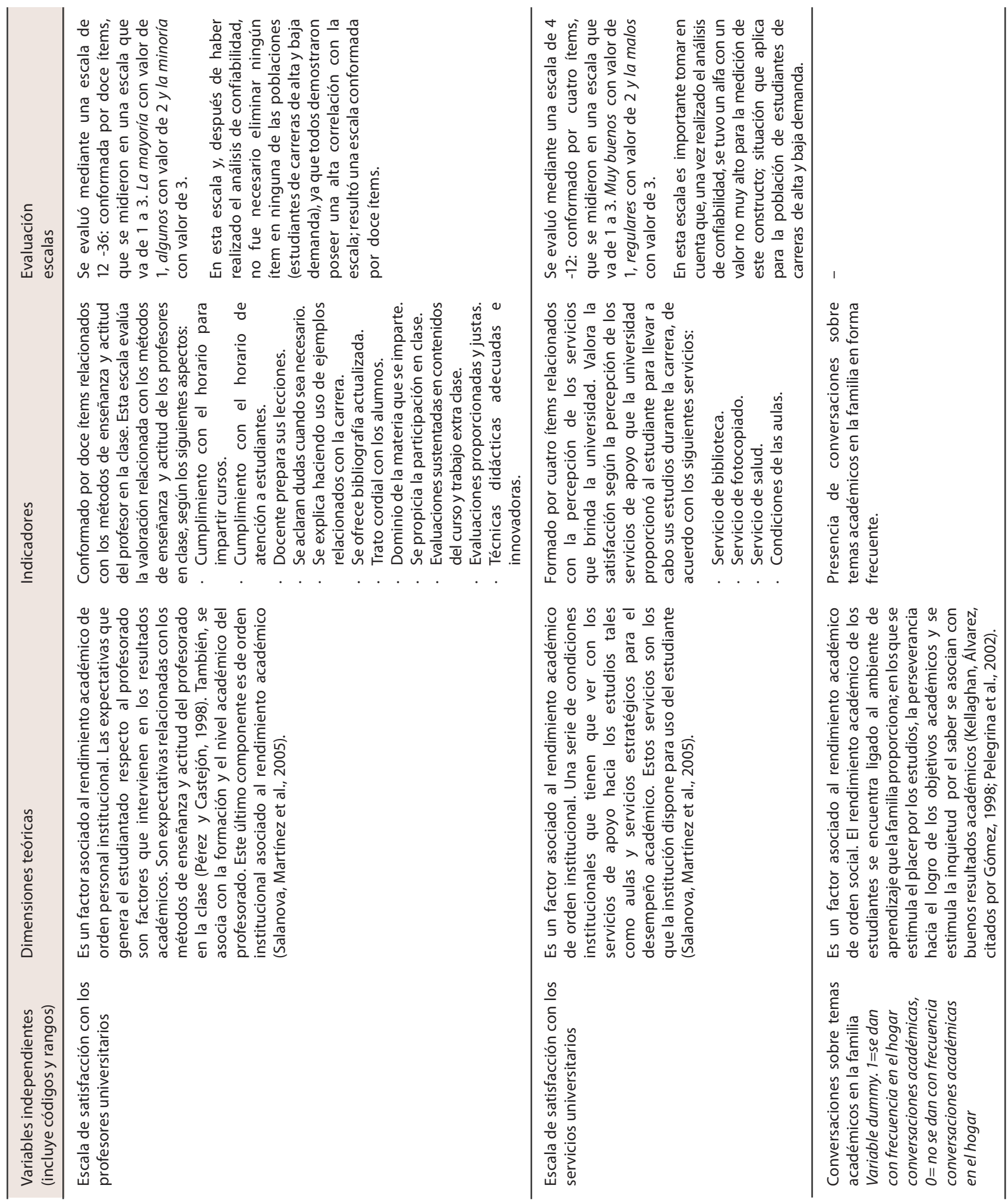
URL: http://www.una.ac.cr/educare

CORREO: educare@una.cr
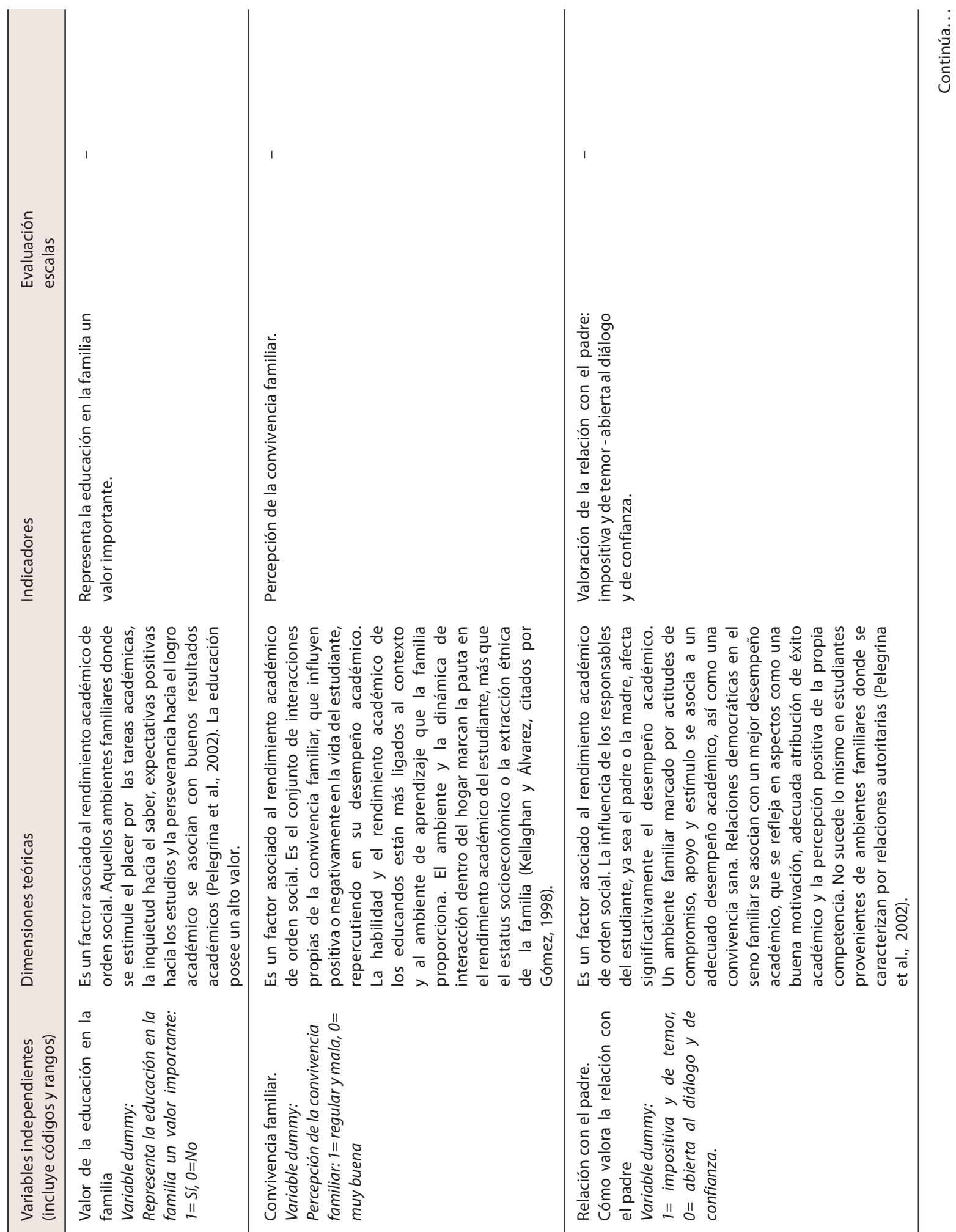
URL: http://www.una.ac.cr/educare

CORREO: educare@una.cr
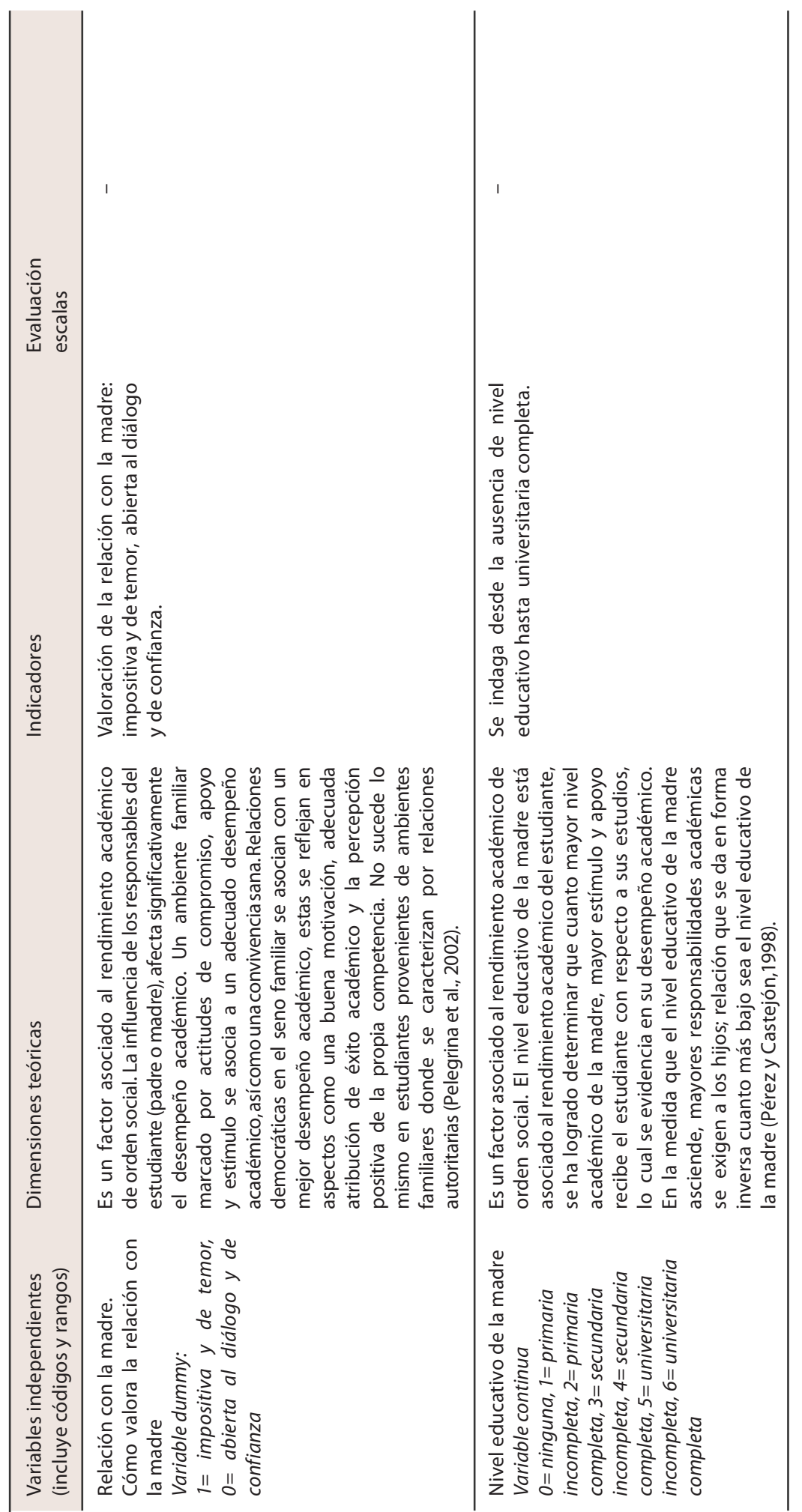

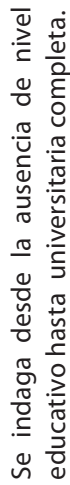
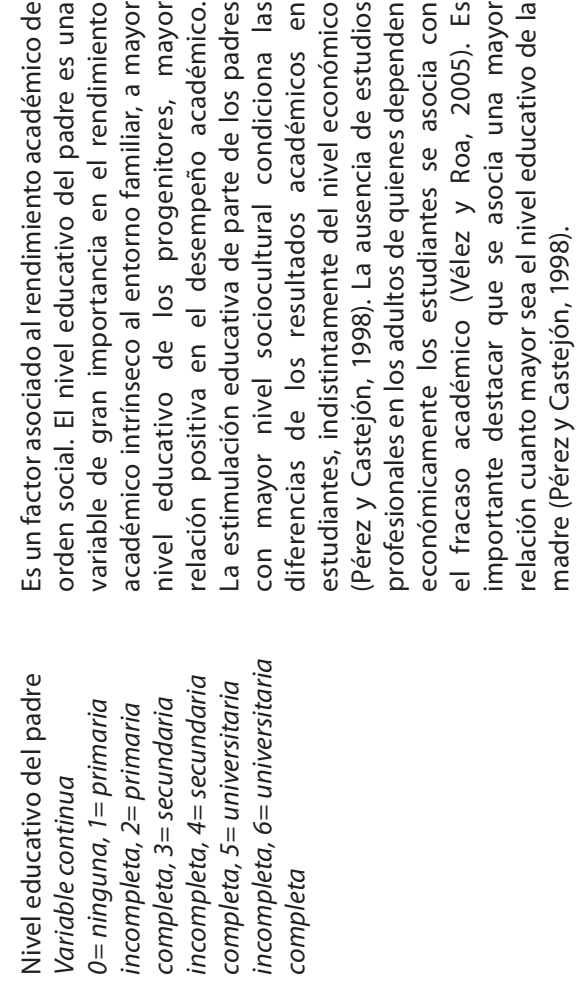
URL: http://www.una.ac.cr/educare

CORREO: educare@una.cr
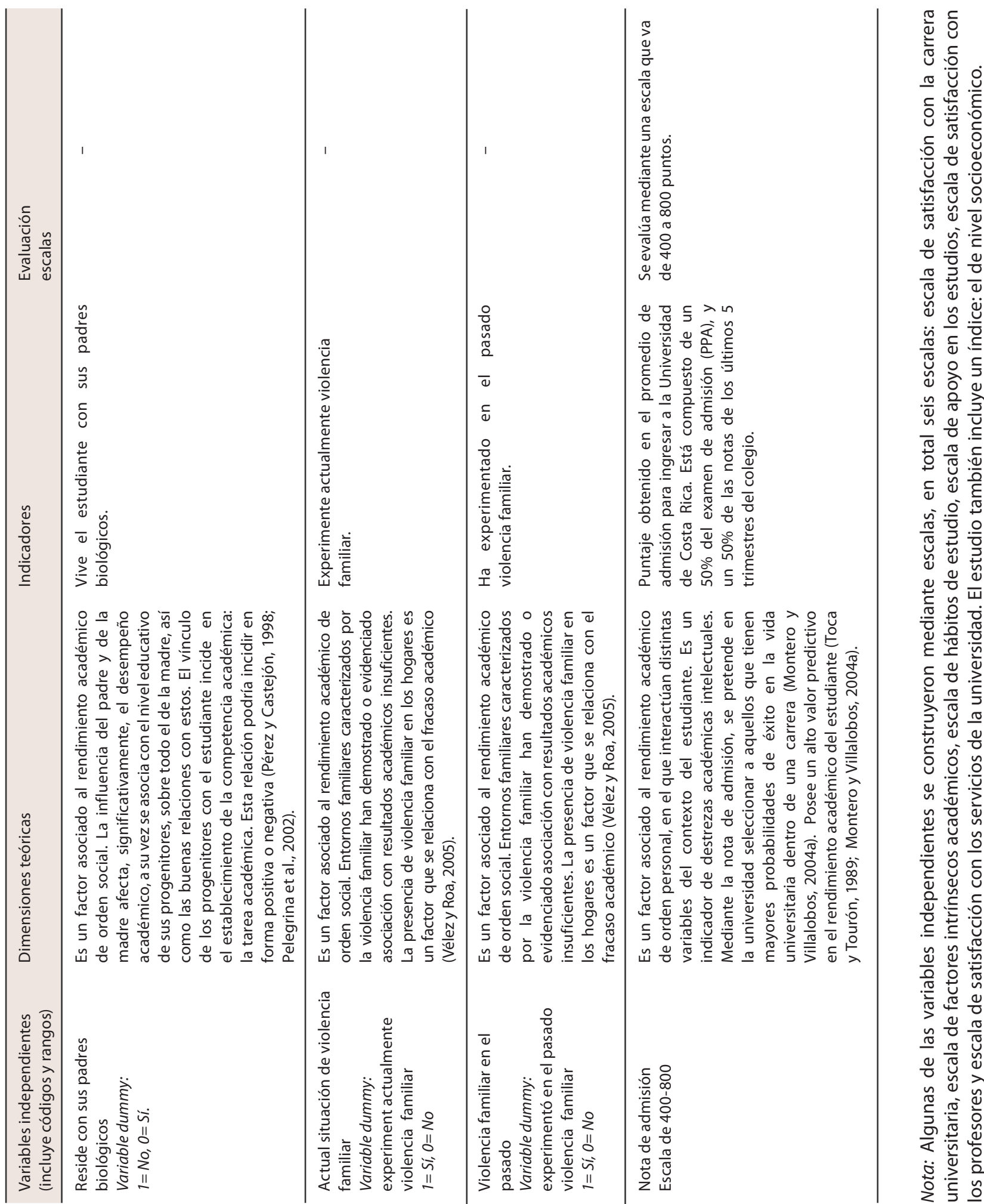
URL: http://www.una.ac.cr/educare

CORREO: educare@una.cr

\section{Población}

La selección de los estudiantes se hizo utilizando una cohorte de ingreso. En este caso, aquellos estudiantes universitarios que ingresaron en el 2003, sin importar el nivel académico en que se encuentren, formaron parte de la selección hecha. Se partió del ingreso de 2003, asegurándose así de que, al menos, hayan transcurrido suficientes años de vida universitaria en el momento en que se aplicó el trabajo de campo, a fin de poder tener criterios más claros para la investigación. La información se confrontó con grupos de referencia o comparación con estudiantes que no solicitaron beca por condición socioeconómica.

\section{Componente nivel socioeconómico}

El nivel socioeconómico se trabaja en dos componentes: estudiantes con la máxima categoría de beca a quienes, por su condición socioeconómica, se les otorgó esta categoría, denominados en el estudio como "estudiantes con la máxima categoría de beca" y estudiantes que no solicitaron beca por esta condición socioeconómica, denominados en el estudio como "estudiantes que no solicitaron beca" de carreras de alta demanda y baja demanda. La designación de la agrupación de estos estudiantes se hace según los parámetros que la Oficina de Atención Socioeconómica de la Universidad de Costa Rica posee para asignar la máxima ayuda socioeconómica que por esta condición requiera el estudiante. La Universidad de Costa Rica utiliza distintas categorías de becas por condición socioeconómica, que van de 0 a 11, siendo la 11 la máxima categoría que se asigna a los estudiantes de niveles socioeconómicos más bajos.

Estos estudiantes, para hacerse acreedores de la categoría de beca 11, que los ubica en la condición de estudiantes con la máxima categoría de beca por su condición socioeconómica, la asumen mediante una serie de variables que la Universidad de Costa Rica, desde la Oficina de Atención Socioeconómica establece, los cuales se indicaron al inicio de este artículo.

\section{Sistematización y análisis de los resultados}

\section{Caracterización de la muestra}

La muestra se conformó por ciento veinte estudiantes que ingresaron a la Universidad de Costa Rica en el 2003. De esta población, se seleccionó a sesenta estudiantes con la máxima categoría de beca, distribuidos en carreras de alta demanda y baja demanda. Los otros sesenta estudiantes se seleccionaron por considerarse estudiantes que no solicitaron beca, distribuidos también en carreras de alta demanda y baja demanda.

La edad promedio de la población participante es de 23 años, la mayoría proviene de colegio académicos, diurnos y públicos. La edad promedio de finalización de la secundaria y de inicio de la universidad es prácticamente la misma, es decir, que los jóvenes salieron del colegio 
y casi de inmediato ingresaron a la universidad. La mayoría de estudiantes proviene de colegios públicos y diurnos, y una pequeña población no asistió a educación preescolar.

Respecto de la educación del padre y la madre, la universitaria completa es el nivel educativo que presenta mayor proporción; $44.2 \%$ el padre y $41.7 \%$ la madre. La mayoría de estudiantes no tiene económicamente a cargo ninguna persona. Cerca de la mitad de la población son estudiantes que laboran en época lectiva. Sobre este aspecto hay que tomar en cuenta que los estudiantes de la carrera de Derecho, en el transcurso de sus estudios se insertan, por lo general, en el mundo laboral, con el afán de adquirir experiencia profesional.

Se hizo un análisis de correlación para ver cuán fuerte es la asociación entre la nota de admisión y el promedio ponderado, este resultó tener una correlación de 0.22; no es muy alta, pero sí es significativa a un 5\%, con una significancia de 0.02 .

Cada uno de los grupos (alta y baja demanda) consta de 60 estudiantes. El grupo de baja demanda es el que está formado por una mayor diversidad de carreras, ya que para completar la población del estudio fue necesario abarcar más de una carrera.

El grupo de alta demanda está formado en un $60 \%$ por estudiantes de la carrera de Derecho; esto se debe a que esta carrera contaba con la mayoría de estudiantes de alta demanda $y$, por lo tanto, fueron incluidos en la muestra. Para cada uno de los grupos (alta y baja demanda) se realizó un modelo de regresión múltiple lineal.

En la variable modalidad de colegio, hay diferencias significativas en estudiantes de carreras de alta y baja demanda ( $p=0.00$ en ambos grupos). La mayoría de estudiantes con la máxima categoría de beca provienen de colegios públicos; por el contrario, la mayoría de estudiantes que no solicitaron beca provienen de colegios privados.

Entre estudiantes que no solicitaron beca (sin beca) y con la máxima categoría de beca (beca 11) se encontró que hay diferencias en cuanto a la asistencia a la educación preescolar. Dentro de este grupo, los estudiantes becados son los que mayormente indican no haber asistido a educación preescolar, y los estudiantes sin beca en su mayoría sí asistieron a educación preescolar.

Se observa que el lugar de residencia ofrece diferencias significativas en la población de baja demanda; la mayoría de los estudiantes que no residen con su familia son estudiantes becados en este grupo.

En aquellos hogares donde es frecuente mantener conversaciones académicas, la diferencia significativa está en los estudiantes de baja demanda $(p=0.02)$, y dentro de este grupo son los estudiantes becados quienes indican, en su mayoría, que no es frecuente en su hogar mantener conversaciones académicas.

Hay diferencias significativas en la población de baja demanda en lo referente a si se experimentó en el pasado situaciones de violencia familiar, $(p=0.015)$; en este caso, son la mayoría de estudiantes sin beca los que indican haber experimentado este tipo de violencia en el pasado. 
URL: http://www.una.ac.cr/educare

CORREO: educare@una.cr

\section{Grupo de estudiantes de carreras de alta demanda}

\section{Caracterización}

En estas carreras, parece no existir diferencias significativas en la edad promedio, ni en el tipo de colegio (nocturno y diurno). La carrera que agrupó la mayoría de estudiantes sin beca es la de Derecho, mientras que los estudiantes con beca 11 se distribuyen en el resto de las carreras, principalmente, en la carrera de Dirección de Empresas.

Es importante destacar que el $40 \%$ de los estudiantes que no solicitaron beca (sin beca) y en carreras de alta demanda, trabaja en época lectiva, a diferencia de los que tienen la máxima categoría de beca (beca 11). Sin embargo, esto podría deberse principalmente a que todos los estudiantes sin beca son de Derecho, y en esta carrera se acostumbra mucho trabajar en un bufete desde los primeros años de la carrera, no tanto por la parte económica, si no por la experiencia que se adquiere.

La edad promedio de finalización de secundaria y de inicio de la universidad es prácticamente la misma; es decir, los jóvenes salieron del colegio y casi de inmediato ingresaron a la universidad.

Es una minoría que señala no haber asistido a educación preescolar, siendo la mayoría de estos estudiantes los que pertenecen al grupo de becados 11 .

Pocos estudiantes reportan que tienen bajo su responsabilidad económica a otras personas.

El promedio ponderado no varía, significativamente, entre estudiantes con beca once y sin beca; no se evidencia que la condición socioeconómica marque diferencia alguna en este rubro. Esta situación podría asociarse a que los estudiantes que ingresan a la Universidad de Costa Rica han pasado por diferentes filtros de selección académica; en este caso, son estudiantes que han ganado un espacio en carreras de alta demanda por la nota obtenida en su promedio de admisión, y para ingresar a estas carreras se requiere obtener un promedio de admisión entre los más altos; situación que podría asociarse con el comportamiento señalado en el promedio ponderado.

En el promedio de admisión, la diferencia que se encontró no fue significativa, el promedio fue levemente más alto en los estudiantes que no tienen beca.

Respecto de si es la carrera que deseaba estudiar, en este grupo se observa que un alto porcentaje de estudiantes están cursando la carrera que querían, un $81 \%$, y el $18 \%$ se quedaron en la carrera que no era la deseada. Contrarrestando esta información sobre la condición socioeconómica, se da una mínima diferencia a favor de los estudiantes que no solicitaron beca; es decir, los estudiantes sin beca, donde los estudiantes con la máxima categoría de beca, en este caso la beca 11 son los que tienen mayor porcentaje y afirman no estar en la carrera que deseaban estudiar.

Con respecto a las escalas de satisfacción de la carrera universitaria (Pearson $=0.205$, significancia $=0.119$ ), escala de apoyo a los estudios universitarios (Pearson $=0.310$, significancia $=$ 0.017 ), y la nota de admisión (Pearson $=0.383$, significancia $=0.003$ ), es la nota de admisión la que tiene la mayor asociación con el rendimiento académico. 
Se realizó una prueba de medias, que mide si existen diferencias significativas en algunas variables como nota de admisión, promedio ponderado y las diferentes escalas, entre estudiantes con la máxima categoría de beca (beca 11) y estudiantes que no solicitaron beca (sin beca). En la tabla 2 se muestra que, efectivamente, existen diferencias significativas en las siguientes variables:

- Escala de satisfacción de la carrera universitaria.

- Escala de factores intrínsecos académicos.

- Escala de satisfacción con los profesores,

- $\quad$ índice de nivel socioeconómico.

No es este el caso de la nota de admisión, promedio ponderado, escala de hábitos de estudio, escala de apoyo a los estudios universitarios y escala de satisfacción con los servicios universitarios que presta la universidad. Sí existen diferencias entre algunas variables de la población de estudiantes que no solicitaron beca (sin beca) y con la población de estudiantes con la máxima categoría de beca (beca 11); sin embargo, se mostró que esto no produce diferencias en las variables del promedio ponderado y la nota de admisión.

Seguidamente, en la tabla 2 se ilustra esta información:

Tabla 2

Prueba de medidas para estudiantes sin beca y con beca 11 que estudian carreras de alta demanda

\begin{tabular}{lrrrrr}
\hline \multirow{2}{*}{ Variable } & & & \multicolumn{2}{c}{ Promedios } & \\
\cline { 5 - 6 } & Valor T & Significancia & Sin beca & Beca 11 & Diferencia \\
\hline Nota de admisión & 1,61 & 0,11 & 612,63 & 584,33 & 28,30 \\
Promedio ponderado & 1,20 & 0,23 & 8,32 & 8,11 & 0,21 \\
Escala de satisfacción con la carrera & & & & & \\
universitaria* & $-2,43$ & 0,02 & 15,36 & 16,79 & $-1,44$ \\
Escala de factores intrínsecos académicos* & $-2,99$ & 0,00 & 26,47 & 28,38 & $-1,91$ \\
Escala de hábitos de estudio & $-0,20$ & 0,84 & 8,48 & 8,59 & $-0,10$ \\
Escala de apoyo en los estudios & & & & & \\
universitarios & 1,70 & 0,09 & 15,00 & 13,38 & 1,62 \\
Escala de satisfacción con los profesores & & & & & \\
universitarios* & $-2,23$ & 0,03 & 29,60 & 31,86 & $-2,25$ \\
Escala de satisfacción con los servicios & $-1,75$ & 0,09 & 9,13 & 9,98 & $-0,85$ \\
Nivel socioeconómico* & 7,37 & 0,00 & 70,43 & 21,26 & 49,17 \\
\hline
\end{tabular}

Nota: * Significativamente diferentes a un nivel de significancia del $5 \%$. 
URL: http://www.una.ac.cr/educare

CORREO: educare@una.cr

\section{Grupo de estudiantes de carreras de baja demanda}

\section{Caracterización}

Este grupo se caracteriza por estudiantes de carreras de Economía Agrícola, Archivística, Artes Plásticas, Geología, Educación Especial, Educación Primaria, Orientación, Educación Física, Geografía, Asistente de Laboratorio, Artes Dramáticas y Tecnología de Alimentos.

La distribución de hombres y mujeres es igual según la beca.

El 55\% de estudiantes de esta muestra asistieron a colegios públicos, y de estos el $45 \%$ tiene beca 11 ; otro $5 \%$ con esta misma categoría de beca asistieron a colegios subvencionados. También, al igual que en el grupo anterior, el tipo de colegio diurno es el que predomina, independientemente, de la beca que poseen, del mismo modo se comporta la categoría del colegio, la mayoría vienen de colegios académicos, un $81.7 \%$. La mayoría asistió a educación preescolar.

Parece no haber diferencias en las edades de finalización de la secundaria y de inicio de la universidad entre estudiantes que no solicitaron beca (sin beca) y los estudiantes con la máxima categoría de beca (beca 11).

La mayoría que indica que el nivel académico del padre y la madre es universitaria completa son del grupo de estudiantes que no solicitaron beca (sin beca); pocos estudiantes con la máxima categoría de beca (beca 11) reportan que su padre y madre poseen universitaria completa. De la mayoría de estudiantes con la máxima categoría de beca, sus padres y madres tienen primaria completa.

La mayoría de los estudiantes de este grupo no trabaja y no tiene dependientes económicos; sin embargo, la proporción de los que sí trabajan es casi la misma en estudiantes que no solicitaron beca y los estudiantes con la máxima categoría de beca.

En el promedio o nota de admisión, sí hay diferencias; no obstante, en el promedio ponderado no hay diferencias entre los grupos que no solicitaron beca y los estudiantes con la máxima categoría de beca (sin beca y con beca 11).

El 73\% de esta muestra evidenció que la carrera en la que está empadronado es la carrera que deseaba estudiar cuando ingresó a la universidad, proporción menor a la encontrada en la muestra de estudiantes en carreras de alta demanda, aunque la diferencia no es tan elevada, sí está a favor de los estudiantes ubicados en las carreras de alta demanda (81\%).

\section{Diferencias de medias}

\section{Variables numéricas}

En la tabla 3 se muestran las diferencias en los promedios entre estudiantes con beca 11 y sin beca (estudiantes con la máxima categoría de beca y estudiantes que no solicitaron beca); es decir, sí hay diferencias entre la población sin beca y con beca, las variables que presentan 
diferencias significativas por (beca) condición socioeconómica de este grupo son la nota de admisión, escala de apoyo a los estudios universitarios, escala de satisfacción con los servicios y el nivel socioeconómico.

Las únicas variables que en ambos grupos, es decir, en las carreras de alta y baja demanda, presentan diferencias significativas entre estudiantes con la máxima categoría de beca (beca 11) y los que no solicitaron beca (sin beca), es la escala de apoyo a los estudios universitarios y, por supuesto, el nivel socioeconómico; sin embargo, estas variables no resultaron de importancia práctica y significativa en la predicción del rendimiento académico.

Tabla 3

Prueba de medidas para estudiantes sin beca y con beca11 que estudian en carreras de baja demanda

\begin{tabular}{lccrrc}
\hline & \multicolumn{5}{c}{ Promedio } \\
\hline Variable & Valor T & Significancia & Sin beca & Beca 11 & Diferencia \\
\hline Nota de admisión* & 3,28 & 0,00 & 610,62 & 552,11 & 58,51 \\
Promedio ponderado & 0,25 & 0,80 & 8,19 & 8,14 & 0,05 \\
Escala de satisfacción universitaria & $-1,60$ & 0,12 & 15,67 & 16,47 & $-0,80$ \\
Escala de factores intrínsecos académicos & $-0,42$ & 0,68 & 27,17 & 27,45 & $-0,28$ \\
Escala de hábitos de estudio & 0,80 & 0,43 & 9,20 & 8,90 & 0,30 \\
Escala de apoyo en los estudios & 2,29 & 0,03 & 15,03 & 12,87 & 2,17 \\
universitarios* & & & & & \\
Escala de satisfacción con los profesores & 0,58 & 0,57 & 30,05 & 30,73 & $-0,68$ \\
Escala de satisfacción con los servicios* & $-4,99$ & 0,00 & 7,90 & 10,15 & $-2,31$ \\
Nivel socioeconómico* & 6,80 & 0,00 & 65,56 & 19,44 & 46,12 \\
\hline
\end{tabular}

Nota: * Significativamente diferentes a un $5 \%$.

\section{Variables categóricas}

Al igual que en el grupo de estudiantes de carreras de alta demanda, se calculó el estadístico Eta, para medir la asociación entre cada una de las variables categóricas del estudio y el promedio ponderado.

Lo curioso es que en este grupo, prácticamente ninguna de estas variables está mediana o altamente correlacionada con el rendimiento académico. De hecho, la variable con mayor correlación es la violencia familiar actual y, aun así, la correlación es baja (0.17), según se indica en la tabla 4. 
URL: http://www.una.ac.cr/educare

CORREO: educare@una.cr

Tabla 4

Asociación del promedio ponderado con las variables categóricas estadístico en asociación Eta

\begin{tabular}{|c|c|}
\hline Variables & Promedio ponderado \\
\hline Sexo ( $1=$ hombre, $0=$ mujer $)$ & 0,153 \\
\hline Modalidad del colegio ( $1=$ público, $0=$ privado) & 0,029 \\
\hline Educación preescolar ( $1=$ sí asistió, $0=$ no asistió) & 0,025 \\
\hline Es la carrera que deseaba estudiar $(1=$ sí, $0=$ no $)$ & 0,067 \\
\hline $\begin{array}{l}\text { Lugar de residencia en tiempo lectivo ( } 1=\text { en casa de parientes, residencias } \\
\text { universitarias, apartamento, } 0=\text { en casa de su familia) }\end{array}$ & 0,021 \\
\hline Beca (1=asignación de beca $11,0=\sin$ beca) & 0,034 \\
\hline $\begin{array}{l}\text { Valor de la educación ( } 1=\text { es la educación en la familia un valor importante, } 0=\text { no es } \\
\text { la educación en la familia un valor importante) }\end{array}$ & 0,03 \\
\hline Vive con los padres biológicos $(1=$ sí, o= no) & 0,045 \\
\hline $\begin{array}{l}\text { Experimenta situaciones de violencia ( } 1 \text { = experimenta violencia familiar } \\
\text { actualmente, } 0=\text { no experimenta violencia familiar actualmente) }\end{array}$ & 0,174 \\
\hline $\begin{array}{l}\text { Experimentó situaciones de violencia ( } 1=\text { experimentó violencia familiar en el } \\
\text { pasado, } 0=\text { no experimentó violencia familiar en el pasado) }\end{array}$ & 0,03 \\
\hline $\begin{array}{l}\text { Conversaciones de temas académicos ( } 1=\text { se da con frecuencia en el hogar } \\
\text { conversaciones académicos, } 0=\text { no se da con frecuencia conversaciones académicas) }\end{array}$ & 0,016 \\
\hline $\begin{array}{l}\text { Convivencia familiar ( } 1=\text { considera que la convivencia familiar es regular y mala, } 0= \\
\text { considera que la convivencia familiar es muy buena) }\end{array}$ & 0,14 \\
\hline $\begin{array}{l}\text { Relación con el padre ( } 1=\text { relación impositiva y de temor, } 0=\text { relación abierta al } \\
\text { diálogo y de confianza) }\end{array}$ & 0,044 \\
\hline $\begin{array}{l}\text { Relación con la madre ( } 1=\text { relación impositiva y de temor, } 0=\text { relación abierta al } \\
\text { diálogo y de confianza) }\end{array}$ & 0,015 \\
\hline
\end{tabular}

Otro punto importantísimo por rescatar aquí es que la nota de admisión, que resultó ser una variable con una correlación importante con el rendimiento académico en el grupo de alta demanda, en este grupo fue una de las más bajas $(0,08)$; por lo tanto, resultó ser una correlación no significativa. 
Respecto de las diferencias entre los estudiantes con beca 11 (estudiantes con la máxima categoría de beca) y sin beca (estudiantes que no solicitaron beca) en la población de carreras de baja demanda, se puede decir que existen diferencias entre:

- El "lugar de residencia en época lectiva".

- La "modalidad de colegio".

- La presencia de "conversaciones académicas en el hogar".

- Si se ha "experimentado en el pasado situaciones de violencia familiar".

En la modalidad de colegio hay diferencias significativas entre estudiantes que no solicitaron beca (sin beca) y estudiantes con la máxima categoría de beca (becados 11), tanto en el grupo de alta demanda como el de baja demanda. La mayoría de estudiantes con beca 11 en el grupo de baja demanda proviene de colegios públicos; sucede lo mismo en el grupo de alta demanda.

En el grupo de baja demanda se encontró que hay diferencias en el lugar de residencia en época lectiva entre estudiantes que no solicitaron beca (sin beca) y estudiantes con la máxima categoría de beca (beca 11). La mayoría de estudiantes que no residen en época lectiva con su familia son los becados 11.

Respecto de las conversaciones sobre temas académicos en el hogar, la mayoría de estudiantes que indican no sostener en sus hogares conversaciones sobre temas académicos, son los becados 11.

También, en este grupo de baja demanda hay diferencias entre estudiantes que no solicitaron beca (sin beca) y estudiantes con la máxima categoría de beca (con beca 11), respecto a si experimentaron situaciones de violencia familiar en el pasado. Los estudiantes con la máxima categoría de beca son los que indican, principalmente, haber experimentado en el pasado situaciones de violencia familiar.

De las variables que resultaron con diferencias significativas en el grupo de baja demanda, ninguna de estas resultó ser significativa y de importancia práctica para predecir el rendimiento académico en el modelo.

\section{Conclusiones}

1. El rendimiento académico es altamente multicausal y complejo; es el producto de la interacción de múltiples factores sociales, personales, institucionales- académicos que pueden variar de una población a otra. Su abordaje se ha concentrado en niveles de la educación primaria y secundaria; estudios en el nivel terciario de la educación son escasos.

2. En la población que accede a carreras de alta demanda y entre estudiantes con la máxima categoría de beca (beca 11) y quienes no solicitaron beca (sin beca) sí existen diferencias significativas entre las variables lineales: índice de satisfacción universitaria, índice de hábitos de 
URL: http://www.una.ac.cr/educare

CORREO: educare@una.cr

estudio, índice de apoyo en los estudios universitarios, índice de satisfacción con el profesorado e índice de nivel socioeconómico; sin embargo, se mostró que no producen diferencias en las variables más importantes, como son el promedio ponderado y la nota de admisión.

3. Finalmente, en la población que accede a carreras de alta demanda, las siguientes variables resultaron de importancia práctica; sin embargo, no son significativas; es decir, no ayudan a predecir el rendimiento académico $y$, por tanto, el resultado no se puede generalizar: sexo, edad, escala de hábitos de estudio, residencia en tiempo lectivo, escala de apoyo, nivel académico de la madre, escala de satisfacción con el profesorado y escala de satisfacción con los servicios.

4. Un elemento de mucha importancia en estudiantes que acceden a carreras de baja demanda es que la nota de admisión, una variable con una correlación importante con el rendimiento académico en los estudiantes que acceden a las carreras de alta demanda; en el grupo de baja demanda fue una de las más bajas $(0,08)$; por lo tanto, resultó ser una correlación no significativa.

5. Al analizar, en el grupo de estudiantes que accede a carreras de baja demanda, las diferencias en los promedios entre estudiantes con beca 11 y sin beca (estudiantes con la máxima categoría de beca y estudiantes que no solicitaron beca), se encontró que sí hay diferencias entre la población sin beca y con beca. Las variables lineales que presentan diferencias significativas por (beca), condición socioeconómica, de este grupo son: la nota de admisión, la escala de apoyo a los estudios universitarios, la escala de satisfacción con los servicios y el nivel socioeconómico.

6. Las únicas variables métricas que en ambos grupos, es decir, en estudiantes que acceden a las carreras de alta y baja demanda, presentan diferencias significativas entre estudiantes con la máxima categoría de beca (beca 11) y los que no solicitaron beca (sin beca) es la escala de apoyo a los estudios universitarios y, por supuesto, el nivel socioeconómico; sin embargo, estas variables no resultaron de importancia práctica y significativa en la predicción del rendimiento académico.

7. Respecto de las variables categóricas, al analizar si hay diferencias entre los estudiantes con beca 11(estudiantes con la máxima categoría de beca) y sin beca (estudiantes que no solicitaron beca) en la población que accede a carreras de baja demanda, se encontró que sí hay diferencias significativas entre el "lugar de residencia en época lectiva", en la "modalidad de colegio", "la presencia de conversaciones académicas en el hogar" y si "se ha experimentado en el pasado situaciones de violencia familiar". Sin embargo, ninguna de estas variables resultó de importancia práctica y significativa en el modelo.

\section{Referencias}

Armenta, N. G., Pacheco, C. C. y Pineda, E. D. (2008). Factores económicos que intervienen en el desempeño académico de los estudiantes universitarios de la Facultad de Ciencias Humanas de la Universidad autónoma de Baja California. Revista IIPSI, 11(1), 153-165. Recuperado de http://sisbib.unmsm.edu.pe/bvrevistas/investigacion psicologia/v11 n1/pdf/a10.pdf 
Badilla, E. y Sancho, M. (1997). Las experiencias de resiliencia como eje para un trabajo social alternativo (Tesis de licenciatura). Universidad de Costa Rica, San José.

Barberena, M. (2005). El perfil latinoamericano: Demografía y nivel socioeconómico (Segunda parte, Resumen). Armai, 14-24. Recuperado de http://www.amai.org/pdfs/revista-amai/ revista-amai-articulo-20050427 164002.pdf

Camhi, R. y Santander, M. (1998). Mapa de la calidad de la educación. En FLACSO, Chile. Propuestas para mejorar la calidad de la educación en Chile. Santiago, Chile: FLACSO, ILADES, Instituto Libertad y Desarrollo.

Carrión, E. (enero-marzo, 2002). Validación de características al ingreso como predictores del rendimiento académico en la carrera de medicina. Revista Cubana de Educación Médica Superior, 16(1), 5-18. Recuperado de http://scielo.sld.cu/pdf/ems/v16n1/ems01102.pdf

Cohen, E. (setiembre-diciembre, 2002). Educación, eficiencia y equidad: Una difícil convivencia. Revista Iberoamericana de Educación, 30, 105-124. Recuperado de http://www.rieoei.org/ rie30a04.PDF

De Miguel, M., Apocada, P., Arias. J. M., Escudero, T., Rodríguez, S., Vidal, J. (2002). Evaluación del rendimiento en la enseñanza superior. Comparación de resultados entre alumnos procedentes de la LOGSE y del COU. Revista de Investigación Educativa, 20(2), 357-383. Recuperado de http://revistas.um.es/rie/article/view/98971/94561

Garbanzo, G. (2011). Factores asociados al rendimiento académico en estudiantes universitarios desde el nivel socioeconómico: Un estudio en la Universidad de Costa Rica (Tesis doctoral). Universidad de Costa Rica, San José, Costa Rica.

García, M. M., San Segundo, M. J. (2001). El rendimiento académico en el primer curso universitario. En J. Gómez (coord.), X Jornadas de la Asociación de Economía de la Educación (pp. 435-445). Murcia: Universidad de Murcia, Servicio de Publicaciones. Recuperado de http://dialnet.unirioja.es/servlet/libro?codigo $=2613$

Gómez, H. (1998). Educación: La agenda del siglo XXl: Hacia un desarrollo humano. Bogotá:T/M Editores.

González, F. A. (1996). Comprensión lectora y rendimiento académico. Revista Galega de Psicopedagogía, 9(13), 209-224.

Gregorat, J., Soria, R., García, J. y Seco, C. (2009). Rendimiento académico y nivel socioeconómico de los alumnos del ISEF de Catamarca. Argentina: Instituto Superior de Educación Física de Catamarca. Recuperado de http://congresoeducacionfisica.fahce.unlp.edu.ar/ descargables/rendimiento-academico-y-nivel-socioeconomico-de-los-alumnos-del-isefde-catamarca

Marchesi, Á. (mayo-agosto, 2000). Un sistema de indicadores de desigualdad educativa. Revista Iberoamericana de Educación, 23, 135-163. Recuperado de http://www.rieoei.org/ rie23a04.PDF 
URL: http://www.una.ac.cr/educare

CORREO: educare@una.cr

Montero, E. y Villalobos, J. (2004a). Estudio comparativo del promedio de admisión a la Universidad de Costa Rica y sus componentes: Aplicación del año 2001. San José, Costa Rica: SIEDIN.

Montero, E., Villalobos, J. (2004b). Factores institucionales, pedagógicos, psicosociales y sociodemográficos asociados al rendimiento académico y a la repetición estudiantil en la Universidad de Costa Rica. (Informe final proyecto 723-A0-174). San José, Costa Rica: Universidad de Costa Rica, Instituto de Investigaciones Psicológicas.

Montero, E., Villalobos, J. y Valverde, A. (2007). Factores institucionales, pedagógicos, psicosociales y sociodemográficos asociados al rendimiento académico en la Universidad de Costa Rica: Un análisis multinivel. RELIEVE, 13(2), 215-234. Recuperado de http://www. uv.es/RELIEVE/v13n2/RELIEVEv13n2 5.pdf

Oliver, J. C., Rosel, J. y Jara, P. (2000). Modelos de regresión multinivel: Aplicación en psicología escolar. Psicothema, 12(3), 487-494. Recuperado de http://www.redalyc.org/articulo. oa?id=72712324

Pelegrina, S., García, M. C., Casanova, P. F. (mayo, 2002). Los estilos educativos de los padres y la competencia académica de los adolescentes. Infancia y aprendizaje: Journal for the Study of Education and Development, 25(2), 147-168.

Pérez, A. M. y Castejón, J. L. (1998). Un modelo causal-explicativo sobre la influencia de las variables psicosociales en el rendimiento académico. Bordon. Revista de pedagogía, 50(2), 171-185.

Pérez, A., Ramón, J. y Sánchez, J. (2000). Análisis exploratorio de las variables que condicionan el rendimiento académico. Sevilla: Universidad Pablo de Olavide.

Programa de Naciones Unidas para el Desarrollo (PNUD). (1998). Educación: La agenda del siglo 21 hacia un desarrollo. Bogotá: Tercer Mundo Editores.

Programa Estado de la Nación en Desarrollo Humano Sostenible. (2009). Decimoquinto Informe Estado de la Nación en Desarrollo Humano Sostenible. San José, Costa Rica: Autor.

Rivero, J. (1999). Educación y exclusión en América Latina. Reformas en tiempos de globalización. Lima: Tarea.

Rodríguez, S., Fita, E., Torrado, M. (mayo-agosto, 2004). El rendimiento académico en la transición secundaria-universidad. Revista de Educación, 334, 391-414. Recuperado de http://www. doredin.mec.es/documentos/008200430373.pdf

Salanova, M., Martínez, I. M., Bresó, E., Llorens, S., Grau, R. (junio, 2005). Bienestar psicológico en estudiantes universitarios: Facilitadores y obstaculizadores del desempeño académico. Anales de Psicología, 21(1), 170-180. Recuperado de http://www.um.es/analesps/v21/ v21 1/16-21 1.pdf 
Salanova, M., Cifre, E., Grau, R. M., Llorens, S. y Martínez, I. M. (2005). Antecedentes de la autoeficacia en profesores y estudiantes universitarios: Un modelo causal. Revista de Psicología del Trabajo y de las Organizaciones, 21(1-2), 159-176. Recuperado de http:// www.redalyc.org/articulo.oa?id $=231317039010$

Toca, M. T. y Tourón, J. (1989). Factores del rendimiento académico en los estudios de arquitectura. Revista de Investigación Educativa, RIE, 7(14), 31-48.

Tonconi, J. (enero, 2010). Factores que influyen en el rendimiento académico y la deserción de los estudiantes de la Facultad de Ingeniería Económica de la UNA-PUNO, período 2009. Cuadernos de Educación y Desarrollo, 2(11), Recuperado de http://www.eumed.net/rev/ ced/11/jtq.htm

UNESCO. (2002). Primera reunión intergubernamental del proyecto regional de educación para América Latina y el Caribe. Proyecto Regional de Educación para América Latina y El Caribe. Recuperado de http://www.tarea.org.pe/images/PRELAC Educ.pdf

Universidad de Costa Rica. Oficina de Becas y Atención Socioeconómica. (2009). Becas. San José, Costa Rica: Autor.

Valle, A., González, R., Núñez, J. C., Rodríguez, S. y Piñeiro, I. (1999). Un modelo causal sobre los determinantes cognitivo-motivacionales del rendimiento académico. Revista de Psicología General Aplicada, 52(4), 499-519. Recuperado de http://dialnet.unirioja.es/ servlet/articulo?codigo $=2498648$

Vélez, A. y Roa, C. N. (2005). Factores asociados al rendimiento académico en estudiantes de medicina. En PSIC. Educación Médica, 8(2), 74-82. Recuperado de http://scielo.isciii.es/pdf/ edu/v8n2/original1.pdf

\section{Cómo citar este artículo en APA:}

Garbanzo, G. M. (2013). Factores asociados al rendimiento académico en estudiantes universitarios desde el nivel socioeconómico: Un estudio en la Universidad de Costa Rica. Revista Electrónica Educare, 17(3), 57-87. Recuperado de http://www.revistas.una.ac.cr/index.php/EDUCARE/issue/current

Nota: Para citar este artículo en otros sistemas puede consultar el hipervínculo "Como citar el artículo" en la barra derecha de nuestro sitio web:

http://www.revistas.una.ac.cr/index.php/EDUCARE/index 